\title{
"Brush recanalization" of a challenging biliary stricture after liver transplantation: a novel application for an old device
}

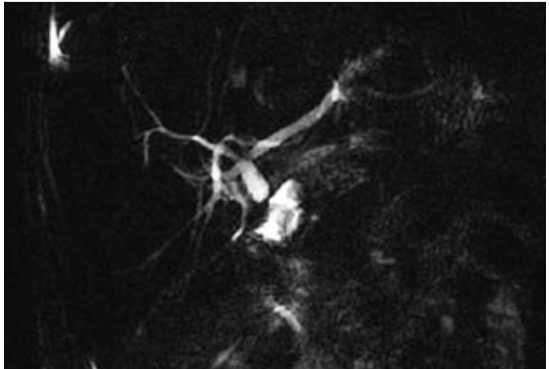

Fig. 1 Magnetic resonance image of the anastomotic stricture in a 34-year-old man who had undergone orthotopic liver transplantation.

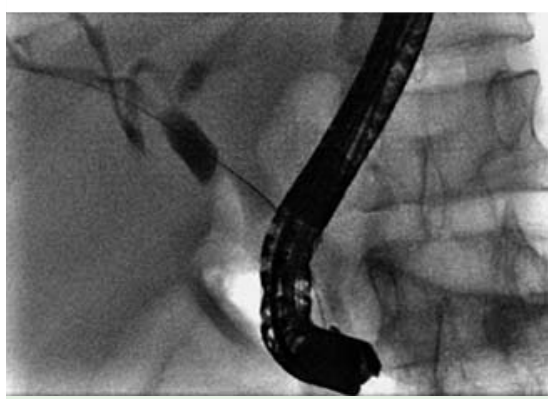

Fig. 2 Cholangiogram showing the anastomotic stricture, which was passed only by the guidewire.

A 34-year-old gentleman, who had undergone orthotopic liver transplantation (OLT) for idiopathic fulminant hepatic failure in November 2004, presented with jaundice and abnormal liver function tests. Magnetic resonance imaging (MRI) identified an anastomotic biliary stricture with dilated intrahepatic ducts, which were also confirmed at endoscopic retrograde cholangiopancreatography ( $\bullet$ Fig. 1$)$.

Although a 0.035-inch hydrophilic guidewire (Acrobat; Cook Medical, WinstonSalem, NC, USA) was passed through the anastomosis, the stricture was not negotiable with standard dilation catheters or with a Soehendra tapered $4 \mathrm{~F}$ dilator (SBDC-6; Cook Medical) ( $\bullet$ Fig. 2).

As a last resort, "brush recanalization" with an RX-wire-guided cytology brush (Boston Scientific Corp., Natick, MA, USA) was used to treat the stricture. Under endoscopic and fluoroscopic control, the duodenoscope was gently advanced into the duodenum in order to straighten the

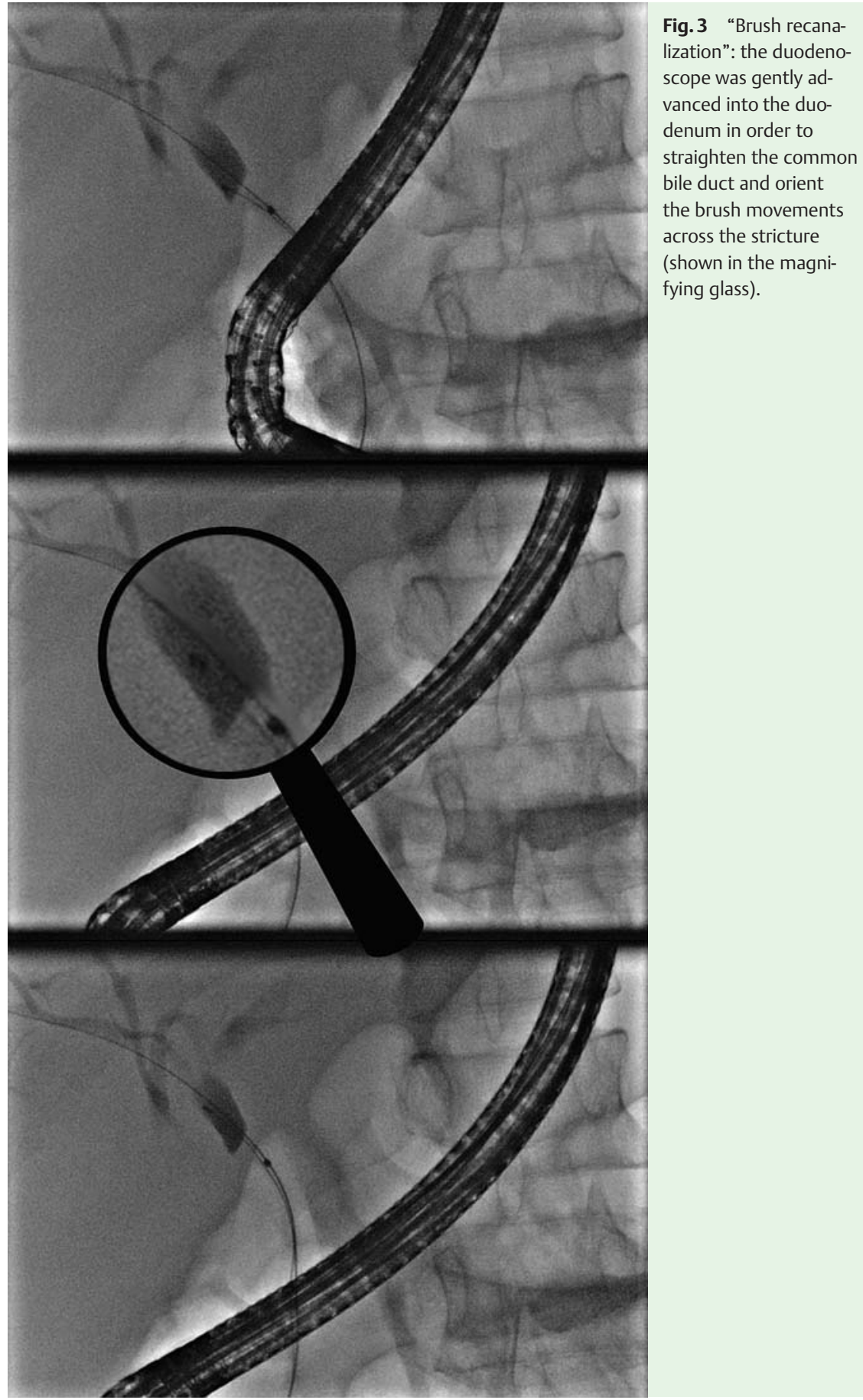

common bile duct and allow us to orient the brush movements precisely in the direction of the stricture. Surprisingly, the brush advanced successfully through the stricture, possibly due to the stiffness of the brush catheter ( $\bullet$ Fig.3). The $8 \mathrm{~F}$ brush catheter was then pushed through the stricture, resulting in further dilation. Finally an $8 \mathrm{~cm}$ long, $10 \mathrm{~mm}$ Niti-S biliary, fully covered, self-expandable metal stent (Taewoong Medical Co. Ltd., Seoul, South Korea) was placed across the stricture to 


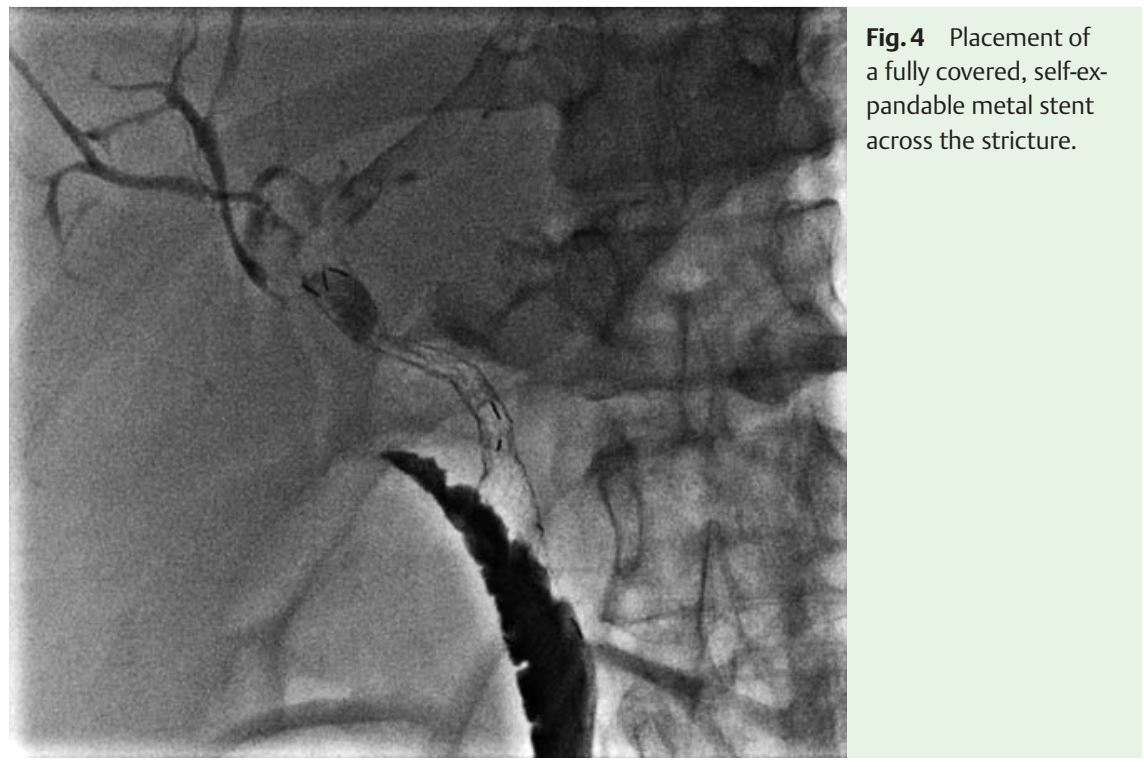

re-establish bile flow ( $\bullet$ Fig.4). No early or late complications were observed.

Biliary strictures are challenging situations in patients who have undergone liver transplantation, occurring in up to $15 \%$ of cases $[1,2]$. In untraversable strictures, biliary recanalization with video cholangioscopy [3], with a specific puncture needle [4] and with a regular needle-knife [5] have all been described.

In the present case, "brush recanalization" involved a novel application of an old and well-known device to treat a challenging anastomotic biliary stricture. In cases where standard procedures fail, it may be both useful and feasible. However, this technique should be carried out only in highly experienced centers familiar with these specialized procedures.

Competing interests: None

\section{Gabriele Curcio ${ }^{\text {, Antonino Granata1, }}$ Neville Azzopardi ${ }^{1}$, Patrizia Sanna ${ }^{1}$, Luca Barresi ${ }^{1}$, Ilaria Tarantino ${ }^{1}$, Roberto Miraglia², Mario Traina ${ }^{1}$}

${ }^{1}$ Gastroenterology and Endoscopy Unit, Mediterranean Institute for Transplantation and Advanced Specialized Therapies (ISMETT), Palermo, Italy

2 Department of Radiology, Mediterranean Institute for Transplantation and Advanced Specialized Therapies (ISMETT), Palermo, Italy

\section{References}

1 Akamatsu N, Sugawara Y, Hashimoto D. Biliary reconstruction, its complications and management of biliary complications after adult liver transplantation: a systematic review of the incidence, risk factors and outcome. Transpl Int 2010; 24: 379-392

2 Tarantino I, Traina M, Mocciaro F et al. Fully covered metallic stents in biliary stenosis after orthotopic liver transplantation. Endoscopy $032012 ; 44: 246-250$

3 Itoi T, Ishii $K$, Tsuji $S$ et al. Diagnostic videocholangioscopy using narrow-band imaging and recanalization by rendezvous technique for difficult benign biliary stricture. Dig Endosc 2009; 21: $108-112$

4 Gupta K, Aparicio D, Freeman ML et al. Endoscopic biliary recanalization by using a needle catheter in patients with complete ligation or stricture of the bile duct: safety and feasibility of a novel technique (with videos). Gastrointest Endosc 2011; 74: $423-$ 428

5 Martins FP, De Paulo GA, Macedo EP et al. Endoscopic biliary recanalization with a needle-knife in post liver-transplant complete anastomotic stricture. Endoscopy 2012; 44 (Suppl. 02): E304-305 